\title{
El retorno de los saberes de subsistencia
}

\author{
Jean Robert \\ Cuernavaca, Morelos, Mexico. Email: jeanrobert37@gmail.com
}

\begin{abstract}
Resumen: La crisis económica es lo que Illich llamaba "una crisis verdadera” porque admite dos soluciones opuestas: 1 . aumentar las dependencias hacia los mercados; 2. renunciar selectivamente a ciertas mercancías y servicios. Este texto aboga por la segunda solución. Para volverla posible, la historia y la epistemología de la economía serán más importantes que todas las micro- y macroeconomías. De optarse por la primera solución, sólo se incrementará una característica de la economía moderna que es su capacidad de engendrar cumbres de riqueza al lado de abismos de miseria. Vista como una invitación a la renuncia selectiva, la crisis puede ser un estímulo a las verdaderas opciones políticas, es decir las opciones que consideran seriamente el retorno de saberes de subsistencia que fueron avasallados por el sistema económico.
\end{abstract}

Palabras clave: Subsistencia, escasez, pobreza y miseria (como realidades distintas), guerras epistémicas.

\section{The return of the knowledges of subsistence}

\begin{abstract}
The economic crisis is what Illich called «a real crisis» because it supports two opposite solutions: 1 . increasing dependencies to markets; 2. selectively renounce to certain goods and services. This paper argues for the second solution. To make it possible, the history and epistemology of economics are more important than all the micro-and macroeconomics. Choosing the first solution will only increase a characteristic of modern economy which is its ability to generate wealth summits alongside depths of misery. Seen as an invitation to selective renunciation, the crisis can be a stimulus to the real policy options, that is, the options that seriously consider the return of subsistence knowledges that were subjugated by the economic system. epistemic wars

Key words: Subsistence, scarcity, poverty and misery (as distinct realities),
\end{abstract}

\section{O retorno dos conhecimentos de subsistência}

Resumo: A crise econômica é o que Illich chama "uma crise real”, porque ele suporta duas soluções opostas: 1. dependências crescentes para os mercados; 2. seletivamente renunciar a certos bens e serviços. Este artigo defende a segunda solução. Para tornar isso possível, a história e epistemologia da economia é mais importante do que todas as micro e macroeconomias. Optar pela primeira solução, só vai aumentar uma característica da economia moderna é a sua capacidade de gerar cimeiras de riqueza ao lado dos abismos da miséria. Visto como um convite à renúncia seletiva, a crise pode ser um estímulo para as opções políticas reais, ou seja, opções que buscam seriamente em voltar conhecimentos de subsistência y 
que foram oprimidos pelo sistema econômico.

Palavras-chave: Subsistence, escassez, pobreza e miséria (como realidades distintas), Guerras epistêmicas

En Némesis médica, libro publicado en 1976, Iván Illich escribía:

Los agudos problemas de personal, dinero, acceso y control que acosan a los hospitales en todas partes pueden interpretarse como síntoma de una nueva crisis en el concepto de la enfermedad. Ésta es una crisis verdadera porque admite dos soluciones opuestas y ambas hacen anticuadas a los hospitales actuales. La primera solución consiste en aumentar la medicalización patógena de la asistencia a la salud, expandiendo más aún el control clínico de la profesión médica sobre la población ambulatoria. La segunda es una desmedicalización crítica, científicamente justa del concepto de enfermedad (Illich, 176:222).

Algo del análisis de la crisis de la medicina hospitalaria de final de los años 1970 se puede aplicar al examen de la crisis de la economía en 2008-2009. De ésta última, también se puede decir que es una crisis verdadera porque 1) admite dos actitudes políticas opuestas y 2) vuelve anticuados la mayoría de las ideas corrientes sobre lo que es verdaderamente la economía. Las dos políticas opuestas frente a la crisis de la economía son, por un lado, un incremento patógeno de la dependencia de la gente hacia los mercados y por otro, una renuncia selectiva, progresiva, crítica y científica a ciertas mercancías y algunos servicios.

La crisis de la medicina hospitalaria de hace treinta o cuarenta años desembocó en la transformación de la medicina en un sistema biomédico tentacular y el aumento concomitante de la medicalización patógena de la sociedad y de los costos médicos. Mi esperanza se funda en mi convicción que la crisis actual de la economía es una invitación a la segunda opción política.

Pero, el autor de Némesis médica insistía también en que "[1]a epistemología médica es mucho más importante para la solución sana de ésta crisis que la biología y la tecnología médica” (Ibid). En analogía, pienso que la epistemología y la historia de la economía son, hoy, mucho más importantes que toda la micro y la macroeconomía. La crisis es un momento en que debemos plantear preguntas radicales sobre las certidumbres poco cuestionadas que sirven de axiomas a los teoremas sociales que servían de guías a las prácticas durante el período que se acaba bajo nuestros ojos.

\section{Tenerle miedo al miedo}

De dos cosas una: la crisis, o es una incitación al miedo, al pánico que el capitalismo requiere para efectuar los reajustes estructurales sin los 
cuales no logrará sobrevivir, o es una oportunidad de tocar fondo, es decir de cuestionar a fondo ideas recibidas demasiado tiempo como verdades intocables. Quiero primero reflexionar sobre la segunda opción, que contrariamente a la primera, es verdaderamente política. Tocar fondo quiere decir recobrar dolorosa y a veces gozosamente la percepción de lo concreto: no solamente de lo duro que se vuelve ganarse la vida, sino también del suelo y de los otros elementos y de la posibilidad, siempre abierta, de la convivencialidad. Significa limpiar su mirada de espejismos y quizás de un exceso de abstracciones, pero también recordar que, en épocas no muy lejanas como en muchísimos lugares del campo mexicano, la gente extraía directamente de la tierra, de las aguas y del aire la mayor parte de lo necesario para su subsistencia. No solitariamente, sino solidariamente.

Acabo de escribir una palabra muy desprestigiada por los economistas: subsistencia. En primera aproximación, llevar una vida de subsistencia es cultivar lo que uno come y comer lo que se cultiva. Donde hay suelo, agua y sol, y, pienso yo, buena convivencia, casi siempre se puede hacer, en plena tierra o en macetas. No requiere títulos ni de primaria ni de licenciatura y aún menos de doctorado, pero exige conocimientos precisos, apropiados al lugar, adecuados a su clima y en armonía con la cultura particular de éste suelo, ésta agua y éste sol, llamémoslos saberes de subsistencia. Pero, ¿no se suele decir, del que cultiva lo que come y come lo que cultiva: “el pobre, apenas logra llevar una vida de subsistencia”? Los más empecinados promotores de éste desprecio son los economistas. Pero, ¿a caso los economistas entienden lo que desprecian? ¿Existe, para ellos, un "fondo" de la economía que se pueda tocar, una base concreta que la relacione con actividades que permitan comer, vestir y abrigarse? La respuesta de los economistas es: la economía es un juego que debería permitir a todos ganar el dinero necesario para obtener la "canasta básica”, a pocos llevar una vida llena de lujos y a poquísimos ostentar una riqueza que ninguna sociedad del pasado pudo siquiera haber soñado. No tienen dificultad en reconocer que eso es injusto, pero, arguyen, hay que distinguir cuidadosamente la cuestión de la justicia de la de la eficacia ${ }^{1}$ de la economía (Kolm, 1967). Es ésta última cuestión que, a los economistas, les interesa. Ven la economía como una lotería, pero, dicen: "seamos realistas: hay un nivel de injusticia óptimo, en el sentido que, de haber menos injusticia, la situación de los ciudadanos más pobres sería peor de lo que es bajo el supuesto óptimo de injusticia”2 . Esto dicen los economistas, o decían hasta el derrumbe de sus ilusiones en el 2008.

Pero vayamos por pasos: hay dos argumentos en lo que acabo de escribir, dos argumentos que es importante diferenciar. El primero dice: de acuerdo, el sistema económico es injusto, pero un poco de injusticia sirve para incrementar la producción de tal manera que algo de la extrema riqueza de los más ricos filtrará hacia los pobres, lo cual queda por ver. El segundo argumento es el más importante, pero es menos evidente. En la sociedad económica moderna, uno generalmente produce una cosa para obtener otra. Quiero una canasta llena para mi familia al fin de la quincena, pero, para obtenerla, lleno papeles en una oficina o trabajo en una fábrica de armas o 
de cigarros. En palabras precisas: sólo obtengo la canasta de mi familia mediante un rodeo. Aun más que la injusticia, el rodeo de producción caracteriza la economía moderna. Jean-Pierre Dupuy escribe al respecto: "Algunos trabajan por ejemplo en la producción de instrumentos de muerte con el fin de obtener un "valor" - su salud - que hubieran en gran medida podido producir de manera autónoma, llevando una vida más sana e higiénica” (Dupuy, 2002: 38-39). El "rodeo de producción” - dar pasos atrás para brincar mejor o sembrar parte de sus granos en vez de comerlos - es inherente a la inteligencia humana, pero todo indica que la finalidad de la sociedad industrial ya no es la producción en sí, sino la producción de rodeos de producción, es decir la producción de "trabajo" o mejor dicho, de "necesidad de trabajo". Si es así, añade Dupuy, la sociedad industrial se ha vuelto estúpida a fuerza de ser inteligente. Antes del 2008, tanto la injusticia inherente a la economía como el alargamiento de los rodeos de producción se justificaban con el argumento que, al crecer el montón de dinero, de bienes y de empleos, finalmente, habrá para todos.

En este artículo quiero exponer dos cosas distintas. La primera concierne los justificados temores respecto al crecimiento de las injusticias que acompañará inevitablemente eventuales ajustes estructurales del sistema económico. Es posible que, en cuestiones de meses o años, los pilotos de la máquina económico la logren sacar de la zona de turbulencias en la que se encuentra, pero, de ser así, en nombre de la seguridad, se habrán aumentado los niveles de control, de persecución de las autonomías y de represión de las disidencias, reduciendo aun los márgenes de libertad de los ciudadanos como usted y yo. Pero hay otra realidad, más profunda, para cuya denuncia apenas empiezan a existir palabras. Esta realidad es una guerra que, en América, se desató con la Conquista: la guerra contra la subsistencia de los pueblos. Como lo decía Michel Foucault, se asemeja a un combate entre un vulgar jarro de hierro y una magnífica cerámica. Es la guerra entre la economía y la subsistencia. Para analizar ésta guerra, hay que ir más allá del calificativo "capitalista” y criticar lo que califica: la economía misma, es decir toda asignación de recursos limitados a fines alternativos (léase "ilimitados”), toda creación de valores bajo la presión de la escasez. En el momento en que se define la economía en términos de valores y de escasez, es irremediablemente "capitalista” o "(neo) liberal” y querer redimirla mediante la intervención del Estado no cambia su naturaleza inherentemente capitalista. "No es posible proclamar en tono perentorio que la economía debe volver a ponerse 'al servicio del hombre', haciendo valer que, ya que emergió de nuestras acciones, podemos corregir sus fallas como las de una herramienta. Tampoco podemos afirmar, como lo hace cierta política contestataria, que la economía es una máquina manipulada en la sombra por unos seres malvados y que, deshaciéndonos de ellos, haremos que se ponga otra vez enteramente a nuestra disposición” (Aubenas y Benasayag, 2002: 109). Re-humanizar la economía me parece tan utópico como volver el automóvil amigable con los peatones. Lo que no puede ser cambiado de fondo se debe contener, un tema que quiero volver central a la hora de hacer unos comentarios más 
sobre la guerra contra la subsistencia. Pero antes, abordemos la cuestión de las injusticias inherentes a la economía y su crecimiento en la óptica de los historiadores de la economía.

\section{Himalayas de riqueza al lado de abismos de miseria}

Ahora, hasta el más ciego de los economistas empieza a ver que la economía es una máquina para producir niveles increíbles de riqueza al lado de simas de miseria. Esta última frase requiere algunas explicaciones. Primero, empezando otra vez por el final, hay que decir muy claramente que la miseria no es la pobreza: históricamente es su opuesto. O mejor dicho, la miseria moderna difiere mucho de la pobreza tradicional. Por un lado, es el resultado de la negación y de la persecución de la pobreza y de su cultura de la mutualidad. Por otro lado, la economía formal, la que se enseña en las universidades y se sirve cada vez más en salsa matemática, es una ceguera selectiva adquirida: el economista que se atrevería a quitarse las ojeras exigidas por su oficio dejaría ipso facto de ser economista, como le ocurrió a mi amigo Jean-Pierre Dupuy (2008) que, a fuerza de investigar los fundamentos epistémicos de su ciencia, la economía matemática, descubrió que sus formulas celan situaciones que se parecen más a la violencia sacrificial que a la toma en cuenta de todos los “concernimientos”. Dejó de ser economista y se hizo filósofo.

Me imagino que en años venideros, los historiadores de la economía se sorprenderán de que los economistas de antes del desvelamiento del 2008 no veían lo que los fundadores de la tradición liberal -los primeros “economistas" en el sentido moderno- veían con toda claridad. Es que éstos pioneros de la economía moderna no se consideraban economistas profesionales en el sentido de hoy, sino pensadores generales, que eran también filósofos -como Burke- conocedores de los sentimientos humanos -como Smith- hombres políticos -como Townsend- o empresarios capaces de sacar provecho hasta de las cárceles -como Bentham. La frase que da prurito a los delicados economistas de hoy cuando la pronuncio frente a ellos no hubiera chocado ni a Burke, ni a Townsend ni a Bentham, pero quizás al refinado Adam Smith, amigo de moralistas y teólogos de la gran tradición escocesa. He aquí esta frase:

\section{La economía moderna es una máquina de producir simultá- neamente montones de riqueza ni siquiera imaginables por nuestros ancestros y abismos de miseria que tampoco cono- cieron.}

La podemos reformular de varias maneras, por ejemplo: "La miseria acompaña la riqueza como la sombra acompaña la luz". "La economía ofrece a los hombres llevarlos hacia la abundancia al tiempo que fomenta las formas de escasez que serán la base de nuevas formas de miseria". "Entre más riqueza ostenta una sociedad, menos sus miembros serán capaces de las relaciones de mutualidad que eran naturales entre los pobres históri- 
cos y eran la base de sus redes de subsistencia”. O, en palabras de John M'Farlane en sus meditaciones sobre la pobreza en la nación más rica del siglo XVIII: "No es en las naciones estériles y bárbaras que hay más miseria, sino en las más prósperas y civilizadas” (1772).

Creo que se empieza a entender. Una nación rica debe suprimir sus propias relaciones de subsistencia para que zumben los motores de su economía. Contrariamente al agua en una percoladora, la abundancia de los ricos no penetra la sociedad hasta llegar hasta los pobres, como lo creía Adán Smith. Bentham, el primer empresario que logró realizar ganancias en la administración de una casa de pobres organizada como una prisión modelo, nunca dio crédito a la ingenua teoría smithiana de la "percolación” de las riquezas con la cual, antes del desvelamiento reciente, se habían vuelto a persignar muchos economistas modernos. Con un cinismo franco que restaría votos a cualquier político contemporáneo, Jeremy Bentham pudo afirmar que la tarea del gobierno no consiste en aliviar la miseria sino en incrementar las necesidades de los pobres para volver la sanción del hambre más eficiente. Urgió a los ricos extraviados en la benevolencia reconocer que "[e]n el estado de prosperidad más elevado, la gran masa de los ciudadanos tendrá probablemente pocos recursos fuera del trabajo diario y estará siempre al borde de la indigencia”. El filósofo Edmund Burke, autor de una teoría de lo sublime, abunda en éste sentido, pues, sólo la amenaza de la miseria y del hambre permite a los hombres que su condición destina a los trabajos serviles aguerrirse a los peligros de las guerras y la intemperie de los mares: "Fuera de los apuros de la pobreza, ¿qué podría obligar a las clases inferiores del pueblo a enfrentar todos los horrores que les esperan en los océanos impetuosos y los campos de batalla?” (Burke, 1795). Por si acaso aun no lo entendieran, el filósofo de lo sublime recalca que todas las veleidades de socorrer a los pobres provienen de principios absurdos que profesan cumplir lo que, por la misma constitución del mundo es impracticable: "Cuando afectamos tener piedad por esa gente que debe trabajar - sino el mundo no podría subsistir - estamos jugando con la condición humana” (Ibid). Por tanto, explica, la verdadera dificultad no es socorrer a los hambrientos, sino limitar la impetuosidad de la benevolencia de los ricos. La voz del reverendo Joseph Townsend es consonante con la de éstas autoridades filosóficoeconómicas: “El hambre domará a los animales más feroces, enseñará la decencia y la civilidad, la obediencia y la sujeción a los más perversos. En general, sólo el hambre puede espolear y aguijar a los pobres para hacerlos trabajar” (1784).

Ahora bien, la Iglesia pidió sucesivamente perdón a los judíos por haberlos perseguido, a Giordano Bruno por haberlo quemado vivo, a Galileo por haberlo condenado, pero la Economía nunca pidió perdón a los pobres. Hoy, aprendió simplemente a disfrazar su cinismo estructural atrás de una máscara de evergetismo, entendiendo ésta última palabra en su sentido literal de comisión del bien, añadiendo: ostentosa y desde las cumbres del poder. 


\section{El desvelamiento de lo que los fundadores de la economía veían con claridad y que sus seguidores hacían profesión de ignorar}

Lo que llamamos "la crisis” es un momento en que la lotería económica tiene menos premios de consuelo para los más pobres y en que la ventaja de de los jugadores medianos se reduce cada vez más, mientras que la suerte de los astuciosos de ayer se juega nuevamente en la bolsa y produce, por un lado, nuevos pobres y, por el otro, un nuevo tipo de riqueza que ya no se evalúa en cantidades aritméticamente identificables sino en números que para el hombre común suenan imaginarios: zillones. En México, país otrora orgullosamente pobre, alimentamos el segundo o tercer zillonario del mundo, una hazaña digna de figurar en el Guiness. No he encontrado estadísticas confiables sobre la disparidad de los ingresos en México, pero he aquí un dato americano:

El grupo de los trescientos mil americanos más ricos gana en conjunto tanto cómo ciento cincuenta millones de sus conciudadanos más pobres. A escala del mundo, se dice que los 500 individuos más ricos del mundo ganan tanto cómo los 416 millones más pobres. Mientras tanto, los gastos militares globales -según el Instituto Internacional de Investigación sobre la Paz de Estocolmo (SIPRI)- representaron un montón de 1.339 millones de dólares en $2007^{3}$. Para clausurar ésta danza de los números locos, citemos un dato muy publicitado del Banco mundial según el cual los pobres representarían actualmente 56\% de la población del mundo: 1.200 millones viven con menos de un dólar al día y 2.800 millones con dos dólares o menos (Narayan, 2007) ${ }^{4}$. Otra vez, la objetividad fría de los números oculta una realidad más inquietante: por cierto, la disparidad entre los ingresos no deja de crecer en todo el mundo. Pero, lo que no dicen el Banco ni la ONU ni los economistas porque no parecen tener conceptos para expresarlo es que, hace medio siglo, la mayoría de los hombres aun disponían de saberes y de medios de subsistencia que les permitían vivir dignamente en la pobreza, mientras que hoy, dependen cada vez más de un Mercado que los arroja a la miseria. ¿Por qué? ¿Cómo? Quizás un dato como éste nos puede poner en el camino de una explicación: Según uno de los documentos presentados a la Conferencia de los Jefes de Estados de Johannesburgo en 2002, el conjunto de los países industriales del Norte otorgan a sus agricultores una subvención anual de 350 mil millones, o sea mil millones cada día, para permitirles exportar sus productos agropecuarios en los países pobres, volviendo estos dependientes de alimentos cuyo precio se juega en la bolsa. Éste dumping legalizado por los poderes económico-políticos, sancionado por evergetas (bienhechores) profesionales y las instituciones que los emplean ha contribuido a destruir la base de subsistencia de los pobres y lo hace más que nunca. ¿Y que oímos, ahora que los precios de los granos y otros alimentos básicos en los grandes mercados suben después de haber sido a la baja durante casi treinta años? Incrédulos, oímos a algunos dirigentes políticos del Sur anunciar que, para que sus pueblos sigan comiendo, bajarán o suprimirán los aranceles sobre los ali- 
mentos importados. ¿No hemos de reconocer aquí una vieja estrategia de los monopolios capitalistas? Cuando la guerra de los precios ha eliminado a los competidores, ¿para qué mantener bajos los precios de lo que la gente deberá comprar de todos modos si quiere sobrevivir en un mundo en que los productores autónomos son tratados como discapacitados? Otro dato: hoy en los Estados Unidos, prototipo de los países con agricultura subvencionada, la mayoría de los más pobres no dedica más del 16\% de sus ingresos a la alimentación, mientras que, en los países del Sur, muchos hogares pobres ya gastan la mitad de sus ingresos para comer y algunos ya 75\%. Todo pasa como si el capitalismo estuviera preparando un gran paupericidio (Lappe, 2004, 2007) ${ }^{5}$. Pero ésta siniestra perspectiva sólo podrá volverse realidad en la medida en que cedamos al miedo. Mis amigos y yo esperamos que la "crisis" sea un estímulo a la reflexión sobre las verdaderas opciones políticas. Entendemos que, para que la "crisis” se transforme en la crisis que podrá permitir al sistema económico proceder a los “ajustes estructurales” sin los cuales no sobrevivirá, tiene que ser todo el contrario de una opción política. Tiene que desembocar en un pánico -si me perdonan el pleonasmo- general. Sólo éste pánico podrá transformar la “crisis” en crisis, y sólo una gran crisis puede hacernos tragar las nuevas inequidades, disparidades e injusticias, las nuevas dependencias y los nuevos despojos que los mecánicos de la máquina económica mundial juzgarán necesarios para volver a ponerla sobre sus rieles. El capitalismo es dos cosas: 1. esa máquina económica mundial en sí, 2. la creencia que no hay manera de sobrevivir fuera de ella.

Por lo tanto, no se trata aquí de demostrar la "falsedad” de los teoremas económicos ni de las teorías de, digamos, los premios Nobel de economía que año tras año se nos invita a festejar. Estos teoremas y teorías funcionan mientras se mantienen políticamente las condiciones de escasez sin las cuales no hay formación de valores económicos. El pensamiento político sobre la economía debe abordar la pregunta de fondo que es: ¿que lugar estamos dispuestos a dar en nuestras relaciones comunitarias y sociales a un domino regido por las leyes de la escasez? ¿Debemos seguir permitiendo que contamine todas las relaciones por su lógica utilitarista, o debemos contenerlo dentro de límites que le impidan destruir el conjunto de la sociedad, transformando ésta en "disociedad” o sociedad disociada, según la expresión de Jacques Généreux (2006)?

\section{El otro lado de la luna}

Eso plantea la cuestión del “exterior” de la economía en su sentido moderno, puesto que, si algo ha de contenerla, le es necesariamente exterior. El dilema que estoy evocando aquí es superficialmente análogo a lo que fue la cuestión de la otra cara de la luna para los astrónomos de antes de los viajes espaciales: todos sabían que existe, pero nadie la había visto. La analogía es superficial, porque la otra cara de la economía, todos la han visto, pero, casi todos, sin reconocerla. Escuchen a los comensales que madrugan en los bares en los que han bebido toda la noche: “¡Ándele, com- 
padre, no me desprecie, acepte ésta ‘última’ copita!”. Parecen moverse en un mundo paralelo en el que, en cada intercambio, hay que dar más de lo que se recibe, hasta aplastar al otro bajo despliegues agonísticos de generosidad.

En su Ensayo sobre el don, Marcel Mauss (1925) da éste ejemplo como ilustración de una característica general de los intercambio en la abrumante mayoría de las sociedades preindustriales y premodernas: había, siempre, que devolver más de lo que se había recibido. Frente a este dato antropológico elemental, la economía moderna, el “capitalismo”, el “neo-liberalismo” o, más generalmente, el "utilitarismo”, es la anomalía antropológica que invierte diametralmente las prácticas tradicionales. Lejos de ser la norma de la cual desviarían las sociedades del pasado, es la desviación erigida en “norma” por la arrogancia de la mentalidad moderna. Es la locura vestida de razón ${ }^{6}$.

Ahora que la economía, al arrojar al borde de la miseria hasta a personas otrora prosperas, es más que nunca causa de sufrimiento, la actuación pública de los economistas se parecerá cada vez más a la de los médicos. Al respecto, otra intuición de Ivan Illich nos puede encaminar hacia lo que se puede y lo que no se debe hacer. Como si fueran doctores, los economistas ya pretenden interpretar el malestar de los nuevos pobres con un conjunto de reglas abstractas que sus clientes-pacientes no pueden ni deben comprender. Los instruyen acerca de entidades desencarnadas representadas por curvas y palabras de plástico. Con ello, los economistas intentan franquear un nuevo umbral en la colonización del lenguaje y las personas afectadas por males que ellos contribuyeron a crear quedan aún más privadas de palabras significativas para expresar su angustia frente a expectativas que se cierran.

\section{Contra la mistificación lingüística}

El lingüista Uwe Poerksen, quien estudió las “palabras de plástico” (1995) con las cuales se hacen muchos discursos económicos y políticos, me regaló un pequeño aparato que combina al azar palabras claves de los discursos contemporáneos para formar frases que se parecen a sentenciosas declaraciones de doctos científicos. En seguida, mezclé algunas frases aleatorias producidas por mi aparato con frases pronunciadas por economistas reales. Invito a los lectores a distinguir cuales frases son productos de mi aparato y cuales lo son de cabezas científicas. "Las preferencias organizacionales que guían los mecanismos de cobertura democrática de la deuda externa deben ser más constructivas". "Una justicia competitiva amigable con todos los actores de la economía exige un debate sobre sus futuros bursátiles”. "Hubiera sido mejor si los afectados por la crisis bursátil hubieran reestructurado sus documentos crediticios antes, y no después de su vencimiento”. “Con su ideología de crecimiento cero, los ecologistas objetores de consciencia al desarrollo han caído a una utopía fundamentalista que perjudica la reestructuración de los portafolios bursátiles perdedores”. 
“Las reformas estructurales para evitar el estancamiento en la recesión deben permitir el ingreso de más capitales extranjeros y revisar el esquema de derechos patrimoniales de los ejidos para que se puedan enajenar (vender) o dar en garantía para créditos”.

Para cualquier ciudadano aún desprovisto de inmunidad a las noticias, estas frases evocan la melodía, sino las palabras exactas, de las letanías del capitalismo cotidiano televisivo. Pero la crítica de la mistificación profesional y programada del lenguaje debe ir más allá de la crítica al capitalismo. Doy razón a Ivan Illich: debe ser epistemológica. Subyacente a la expropiación legalizada de la plusvalía del trabajo, a la lucha de clases y a la acumulación del capital, hay una guerra epistémico quizás más fundamentales que todas las otras: una guerra entre saberes cuya forma histórica es la guerra contra la subsistencia.

\section{Guerras epistémicas}

Atrás de los conflictos en torno a la repartición desigual de lo que aún se llama “riqueza”, hay una pugna despiadada entre dos tipos de saberes. Los primeros son empíricos, generalmente transmitidos oralmente, locales y concretos. Los segundos son formalizados o hasta matematizados, conservados por escrito, desterritorializados, desmaterializados, de pretensión universal, y abstractos. En la sociedad contemporánea, los primeros dan prestigio, hacen parecer inteligentes a los que los detienen y dan prestigio y poder. Los segundos han sido tildados de “arcaicos”, “despreciables”, provincianos. Los primeros se catalogan como “científicos” y los otros como retrógrados y obsoletos, o se catalogaban así antes de la crisis de 2008. Los primeros son saberes de subsistencia que permiten vivir a partir de lo que nos dan el suelo, el cielo y las aguas. Los segundos son saberes económicos que permiten obtener de otros, frecuentemente muy lejanos, de hecho, lo más lejanos posible, los elementos de nuestra subsistencia. Los primeros presuponen capacidades concretas, únicas, apropiadas a un lugar, una cultura, un clima: autonomía. Los segundos prosperan cuando el mundo parece haberse transformado en un desierto cultural, un espacio "sin fuegos ni lugares”, abstracto, falsamente universal, desarraigado de todo suelo, toda materia, toda carne. Los primeros saberes son los que se enseñan en las universidades -las “transgénicas” de los ricos, como dijo el Comandante Tacho- y los que abren al éxito profesional, político, científico y social que buscan las élites. El segundo tipo de saberes son los de la gente humilde que no ha roto del todo con su anclaje en una tradición local. 


\section{Notas}

${ }^{1}$ Considerando a los agentes económicos individuales más que a las empresas, una economía perfectamente eficaz aseguraría compensaciones perfectas de los “costos” de cualquier tipo o, en palabras del economista matemático Serge-Christophe Kolm (1967), tomaría en cuenta todos los “concernimientos" de los participantes en el mercado. La idea de una economía perfectamente eficaz es evidentemente una utopía y, en mi modesta opinión, una utopía peligrosa.

${ }^{2}$ Más o menos inspirados por un principio de la teoría de la justicia de Rawls (1971), muchos economistas afirman que una sociedad, concebida como una totalidad aislada de las otras, debe mantener un nivel de injusticia "óptimo" en el sentido que ésta injusticia óptima debe ser estructurada de tal forma que sea benéfica para los menos aventajados.

${ }^{3}$ Le Monde, 11 de junio 2008.

${ }^{4}$ Recientemente, dos autores han criticado la definición de las personas por lo que NO son, NO tienen, NO ganan y la ignorancia de sus verdaderas capacidades, su potencia, su conatus. Ver Rahnema y Robert (2008), libro en el cual algunas de las ideas expresadas en éste articulo se encuentran en forma más elaborada.

${ }^{5}$ Ver las estadísticas presentadas por Frances Moore Lappé (2004; 2007). El dumping practicado mediante subsidios a los agricultores de los países ricos no dista mucho de parecerse a una operación de envergadura mundial para asfixiar a todos los pobres, particularmente a los campesinos de subsistencia. Sin embargo, los datos destinados al público insisten en que, en las condiciones de "urgencia” actuales, sólo una agricultura modernizada podría llegar a alimentar toda la población mundial. Lo que callan los manipuladores de datos es que, hasta recientemente, la agricultura tradicional era capaz de dar de comer a la mayor parte de la gente y que, aún en su estado actual de modernización parcial, la agricultura mundial produce lo suficiente para dos veces la población total del mundo.

${ }^{6}$ Para mí, la iniciación clásica a lo extraño de la normalidad económica moderna es Kart Polanyi (1944). Véase también, la obra de un autoafirmado “discípulo” de Polanyi -autor además del prefacio de la muy tardía traducción de ésta obra al francés-, Louis Dumont (1982). Entre los autores contemporáneos que han mantenido viva la tradición que, desde Aristoteles, sostiene que la "administración de la casa" (todo lo que cubren los verbos oikonoméô y oikodoméô) es radicalmente distinta de toda crematística, definida por Aristóteles como el estado de espíritu fuera de proporción del que entra en intercambios con la intención de obtener más de lo que da y de acumular bienes más allá de todos lo principios de satisfacción -necesariamente limitada- y de saciedad -rapidamente alcanzadadestacan:

Los pioneros: Alexander Chayanov (1966)\}. Chayanov fue ejecutado en 1937 por su oposición tildada de "revisionista" al muy economicista kolkhose, -productor de valores de cambio más que de uso- promovido por los partidarios del capitalismo de Estado disfrazado de socialismo. En 1987, Chayanov fue rehabilitado en Moscú a iniciativa de Gorbachov en una ceremonia presidida por el profesor Teodor Shanin que pudo declarar que, al asesinar a Chayanov, el socialismo soviético se había suicidado; ver el sitio de Teodor Shanin. Tambien véanse: Julius Herman Boeke (1953), y François Partant (1982). 


\section{Bibliografía}

Aubenas, Florence y Benasayag, Miguel (2002), Résister c'est créer. La Découverte. París.

Boeke, Julius Herman (1953), Economics and economic Policies of Dual Societies as Examplified by Indonesia. Institute of Pacific Relations. New York.

Burke, Edmund (1795), Thoughts and Details on Scarcity.

Chayánov, Alexandr; Daniel Thorner, Basile Kerblay, R.E.F. Smith, Teodor Shanin (1986), A.V. Chayánov and The Theory of Peasant Economy. Manchester University Press. Versión española Chayánov y la teoría de la economía campesina. Siglo XXI. México.

Dumont, Louis (1982), Homo aequalis: Génesis y apogeo de la ideología económica. Taurus. Madrid.

Dupuy, Jean-Pierre (2002), Pour un catastrophisme éclairé. Quand l’impossible est certain. Le Seuil. París.

Dupuy, Jean-Pierre (2008), Dans l'oeil du cyclone. Colloque de Cerisy. Carnets Nord. París.

Généreux, Jacques (2006), La Dissociété. Le Seuil. París.

Illich, Ivan (1976), Medical Nemesis. Pantheon Books. New York. Edición española Némesis Médica de 1978 de Juan Tovar. Joaquín Mortiz S.A. México DF. Se cita la versión castellana de Ángelo Ponziano, Integral, Barcelona, 1984. Consúltese también en Obras Reunidas, volumen 1, Fondo de Cultura Económica, México, 2007.

Kolm, Serge-Christophe (1967), «Décisions et concernements collectifs: contribution à l'analyse de quelques phénomènes fondamentaux de l’organisation des sociétés», Analyse et Prévision, IV, pp. 483-497.

La Découverte (1988-1992), La Revue du MAUSS. Éditions de la Découverte, París, trimestral.

Lappé, Frances Moore (2004), World Hunger: 12 Myths. Grove Press. New York.

Lappé, Frances Moore (2007), Getting a Grip: Clarity \& Courage in a World Gone Mad. Chelsea Green Publishing. White River Junction, Vt.

Mauss, Marcel (1925), Essai sur le don. Forme et raison de l'échange dans les sociétés archaïques. Sociologie et anthropologie. PUF. París, pp. 143-279. Versión española Ensayo sobre el don. Forma y razón del inter- 
cambio en las sociedades arcáicas, Tecnos, Madrid, 1979.

M’Farlane, John (1772), Enquiries concerning the Poor.

Narayan, Deepa (2007), Moving out of Poverty: Cross-Disciplinary Perspectives on Mobility. Palgarve, Macmillan, Banco Mundial. New York.

Partant, François (1982), La Fin du développement: naissance d'une alternative. La Découverte. París.

Poerksen, Uwe (1995 [1988]), Plastikwörter, die Sprache eine internationalen Diktatur. Klett-Cotta. Stuttgart. Versión inglesa Plastic Words, the Tyranny of a Modular Language, Pennsylvania University Press. University Park.

Polanyi, Karl (1944), La gran transformación. Crítica del liberalismo económico. Claridad. Buenos Aires. Otras ediciones completas, La Piqueta, Madrid, 1989; FCE, México, 1989. Ambas ediciones corrigen y mejoran la primera y pionera edición de ésta obra al español por la editorial porteña Claridad de 1947.

Rahnema, Majid y Jean Robert (2008), La Puissance des pauvres. Actes Sud. Arles.

Rawls, John (1971), A Theory of Justice. Harvard University Press. Cambridge. Se cita la edición revisada de 1999, Oxford University Press.

Townsend, Joseph (1784), A Dissertation on the Poor Laws.

Recibido: 15.01.2012

Aceptado: 07.11.2012 